\title{
CONTEÚDOS CULTURAIS DO LAZER E PARTICIPAÇÃO MASCULINA EM GRUPOS DE CONVIVÊNCIA PARA IDOSOS DE FLORIANÓPOLIS (SC) ${ }^{1}$
}

Recebido em: 25/03/2015

Aceito em: 05/10/2015

\author{
Priscila Mari dos Santos ${ }^{2}$ \\ Universidade Federal de Santa Catarina (UFSC) \\ Florianópolis - SC - Brasil \\ Alcyane Marinho ${ }^{3}$ \\ Universidade Estadual de Santa Catarina (UDESC) \\ Florianópolis - SC - Brasil
}

RESUMO: Com objetivo de identificar os conteúdos culturais do lazer em Grupos de Convivência para Idosos (GCI) de Florianópolis (SC), focalizando a participação masculina, realizou-se uma pesquisa descritiva exploratória e qualitativa. Participaram 38 homens idosos (média de idade de 69,6 $\pm 13,4$ anos), integrantes de cinco GCI, sendo um grupo de cada Região da cidade (Centro, Norte, Sul, Leste e Continente). Utilizaram-se um roteiro de entrevista semiestruturada com os homens e uma matriz de observação sistemática em quatro encontros de cada GCI. Os dados foram tratados por meio da técnica de análise de conteúdo. Os homens encontram oportunidades privilegiadas para vivenciar os conteúdos culturais do lazer nos GCI, sendo que os conteúdos turísticos e sociais foram identificados nos cinco GCI; os intelectuais e artísticos em quatro GCI (Centro, Sul, Leste e Continente); e os manuais e físicos em dois GCI (Centro e Leste; Sul e Leste).

PALAVRAS CHAVE: Atividades de Lazer. Idoso. Homens.

\section{CULTURAL LEISURE CONTENTS AND MALE PARTICIPATION IN ELDERLY GROUPS OF FLORIANÓPOLIS (SC)}

\footnotetext{
${ }^{1}$ Este estudo faz parte de uma pesquisa mais ampla de dissertação de mestrado, desenvolvida em 2014, a qual objetivou investigar se GCI em Florianópolis (SC) constituem-se em possíveis espaços de lazer para homens idosos.

Para a sua realização, contou-se com apoio financeiro do Conselho Nacional de Desenvolvimento Científico e Tecnológico $(\mathrm{CNPq})$, por meio de concessão de bolsa de mestrado à pesquisadora principal deste estudo.

2 Mestre em Educação Física pela Universidade Federal de Santa Catarina (UFSC). Membro do Laboratório de Pesquisa em Lazer e Atividade Física da Universidade do Estado de Santa Catarina (LAPLAF/UDESC/CNPq).

${ }^{3}$ Doutora em Educação Física pela Universidade Estadual de Campinas (UNICAMP). Professora Adjunta da Universidade do Estado de Santa Catarina (UDESC), no Centro de Ciências da Saúde e do Esporte (CEFID). Professora permanente do Programa de Pós-Graduação em Educação Física da UFSC. Líder do LAPLAF/UDESC/CNPq.
} 
ABSTRACT: This paper intends to identify the cultural leisure contents in Elderly Groups of Florianopolis (SC), focusing on male involvement. The study is an exploratory and descriptive qualitative research, that attended 38 elderly men (mean age $69.6 \pm 13.4$ years old), members of five Elderly Groups, one group of each region of the city (Central, North, South, East and Continent). Semi-structured interviews with men, and systematic observation matrix in four meetings each Elderly Group were used. Data were analyzed by means of content analysis technique. The old men can find privileged opportunities to experience cultural leisure content in the GCI: tourist and social content were identified in five GCI; intellectual and artistic were identified in four GCI (Central, South, East and Continent); and manual and physical in two GCI (Centre and East, South and East).

KEYWORDS: Leisure Activities. Aged. Men.

\section{Introdução}

O termo conteúdos culturais do lazer é uma influência do pensamento de Dumazedier (1980) ao distinguir cinco áreas fundamentais de interesses verificados no lazer (físicos, manuais, artísticos, intelectuais e sociais). Por interesse, o autor entende o conhecimento que está enraizado na cultura vivida. Nesse sentido, os termos conteúdos culturais do lazer e interesses culturais do lazer são entendidos como sinônimos. A palavra cultura, por sua vez, é utilizada de forma ampla para representar as distintas possibilidades de manifestações no lazer (MELO, 2004; MARCELLINO, 2007).

De antemão, deve-se esclarecer que a distinção entre os vários interesses no lazer só pode ser estabelecida em termos de predominância e representando escolhas subjetivas, pois constituem um todo interligado, e não esferas estanques (MARCELLINO, 2007). Assim, uma pessoa pode estar ligada a mais de um interesse em uma mesma atividade no lazer (DUMAZEDIER, 1980; MELO, 2004).

É pertinente ressaltar que, conforme sugestão do sociólogo brasileiro Luiz Octávio de Lima Camargo, há um sexto grupo de conteúdos culturais do lazer, caracterizado pelos interesses turísticos (CAMARGO, 1986). Segundo Marcellino (2007), embora existam, na literatura, outras propostas de grupos de conteúdos, a que 
distingue essas seis áreas de interesses no lazer é a mais aceita entre os estudiosos do tema.

Dessa forma, considerando os seis grupos de conteúdos mencionados, torna-se visível que o lazer compreende a vivência de inúmeras práticas culturais, tais como o jogo, a brincadeira, a festa, o passeio, o esporte, a pintura, a literatura, a dança, o cinema, o ócio, entre outras (GOMES, 2003). Diante disso, surge como desafio atual ampliar o acesso e o conhecimento dos idosos relativos a tais vivências (GOMES; PINHEIRO; LACERDA, 2010). Isso porque, conforme Marcellino (1996), é frequente à restrição das atividades no lazer a um campo específico de interesses por falta de contato com outros conteúdos.

Existem diferentes barreiras que dificultam o acesso ao lazer, tais como o fator econômico, a classe social, o nível de instrução, o acesso ao espaço urbano, a violência, a faixa etária, o sexo e os preconceitos. Especificamente sobre a faixa etária, no caso dos idosos, ainda há condições como a falta de disposição, as dificuldades de saúde e de locomoção e o impacto da interrupção do trabalho profissional pela aposentadoria, as quais, muitas vezes, restringem as vivências no lazer (MARCELLINO, 1983, 1996). No que concerne ao sexo, os homens, particularmente, podem ser mais resistentes a participar de cursos, viagens e outras atividades em grupos (CAMARANO; KANSO; MELLO, 2004), tendo em vista que a saída da esfera laboral pode ser acompanhada de um sentimento de inutilidade, relacionado ao imaginário social supervalorizador do trabalho (MARCELLINO, 1996).

Aspectos demográficos podem igualmente influenciar a diminuição/limitação das atividades no lazer de homens idosos, especialmente daquelas que pressupõem a participação em grupos. A predominância de mulheres na sociedade brasileira também 
atinge o segmento populacional de idosos (IBGE, 2011, 2013), revelando que, embora a velhice não seja universalmente feminina, o envelhecimento possui um significativo componente de gênero (CAMARANO; KANSO; MELLO, 2004).

Compreende-se o termo gênero como construção social do feminino e do masculino, contemplando possibilidades de explicar as diferenças e desigualdades entre homens e mulheres observando-se aspectos sociais, históricos e culturais (GOELLNER, 2004; SCOTT, 1995). Nesse sentido, fica claro que as questões de gênero também se fazem presentes no contexto do lazer. Apesar de, em cada fase da vida, ser possível verificar distinções no usufruto do lazer entre indivíduos do sexo masculino e do feminino - na terceira idade, por exemplo, as mulheres parecem procurar por atividades no lazer com mais frequência que os homens, especialmente no ambiente extradoméstico -, a definição estereotipada de certas práticas culturais como masculinas ou femininas, como o futebol e a dança, respectivamente, parece transcender as gerações (GOELLNER et al., 2009).

Nesse cenário, os Grupos de Convivência para Idosos (GCI) - como espaços destinados ao convívio comunitário por meio de atividades propulsoras da integração social e que atendem determinados interesses no lazer (BRAZ, 2008; BRASIL, 1994; MAZO; LOPES; BENEDETTI, 2009) - têm se deparado com a baixa participação de homens. Essa situação é frequentemente atribuída à priorização de atividades que não atendem aos anseios desses indivíduos; à presença expressiva de mulheres; e/ou à falta de estímulo e de participação do poder público nessas questões (BROD, 2004; KIST, 2011; MAZO, 2003).

Em Florianópolis (SC), quadro regional desta pesquisa, os GCI surgiram mediante parcerias entre a Prefeitura e os órgãos nacionais ligados à assistência social 
no final de 1970. Contudo, foi a partir da promulgação da Política Nacional do Idoso, em 1994, que os GCI difundiram-se pelo país, e, inclusive, por Florianópolis (SC) (ARAÚJO, 2004; BRASIL, 1994; ROLLIN, 1998).

Em 2014 foram identificados, nessa cidade, 103 GCI ativos, cadastrados na Secretaria Municipal de Assistência Social (SEMAS), envolvendo 4.275 participantes (3.976 do sexo feminino e 299 do sexo masculino), com quantidade absoluta maior de mulheres do que de homens em todos os grupos. No entanto, alguns GCI apresentam proporção de homens (em relação à quantidade total de integrantes) um pouco mais elevada quando comparada à proporção de homens de outros grupos localizados em uma mesma Região da cidade, sendo merecedores de investigação (SANTOS; MARINHO, 2014).

Na cidade de Alpestre (RS), por exemplo, Vargas e Portella (2013) identificaram um GCI com quantidade de homens maior que a de mulheres. Esse fato estimulou os autores a investigar os fatores determinantes e o significado da participação masculina no grupo em questão, proposta similar a do presente trabalho. É pertinente destacar que, no referido estudo, o GCI investigado foi idealizado por idosos do sexo masculino e também são eles quem propõem as atividades a serem desenvolvidas (ginástica, passeios, visitas a outros grupos, etc.), o que, segundo Vargas e Portella (2013), pode estar relacionado ao maior número de homens participantes desse GCI.

A pesquisa realizada por Coutinho e Acosta (2009), em três clubes da cidade de Santa Maria (RS) frequentados principalmente por homens idosos, constitui outro exemplo de investigação que trata dos temas lazer e envelhecimento associados ao gênero masculino. Neste caso, também foi constatada a figura masculina na condução das atividades, sendo estas, prioritariamente, jogos de carta, sinuca, bocha e conversas. 
Para além desses dois estudos, há outras (embora poucas) investigações nacionais que oportunizaram vez e voz aos homens idosos no contexto de sua participação em projetos voltados ao lazer, como as pesquisas desenvolvidas por Goellner et al. (2010) e por Mello e Votre (2013), ambas na cidade do Rio de Janeiro (RJ). Todavia, no tocante aos GCI essa lacuna se torna ainda mais acentuada. Apesar de ser possível verificar diversos estudos realizados em GCI no Brasil (BRAZ, 2008; BRITTO DA MOTTA, 1999; BROD, 2004; KIST, 2011) e, especificamente, em Florianópolis (SC) (ARAÚJO, 2004; LOPES, 2012; MAZO, 2003; ROLLIN, 1998), os aspectos investigados geralmente não envolvem diretamente os homens e/ou não abordam efetivamente o lazer, fenômeno que parece se concretizar nesses espaços.

Partindo dessas considerações, este estudo teve como objetivo identificar os conteúdos culturais do lazer desenvolvidos em GCI de Florianópolis (SC), focalizando a participação masculina.

\section{Metodologia}

Esta pesquisa caracteriza-se como descritiva exploratória (MARCONI; LAKATOS, 2007), com abordagem qualitativa dos dados (MINAYO, 2013). Cinco GCI compuseram os contextos desta investigação, tendo sido selecionados a partir de um levantamento da quantidade de participantes nos 103 GCI cadastrados na SEMAS da Prefeitura Municipal de Florianópolis (PMF), por meio de contato telefônico com os coordenadores, em abril de 2014 (SANTOS; MARINHO, 2014). Foi escolhido um GCI de cada Região da cidade (Centro, Norte, Sul, Leste e Continente) que apresentou maior proporção de participantes do sexo masculino em comparação aos demais grupos 
localizados em uma mesma Região. A Tabela 1 apresenta as quantidades de participantes, de ambos os sexos, nos cinco grupos eleitos para este estudo.

Tabela 1 - Quantidade e proporção de homens e mulheres participantes dos cinco GCI selecionados.

\begin{tabular}{|c|c|c|c|c|c|}
\hline \multirow{2}{*}{ REGIÃO GCI } & \multirow{2}{*}{$\begin{array}{c}\text { PARTICIPANTES } \\
\text { (f) }\end{array}$} & \multicolumn{2}{|c|}{ HOMENS } & \multicolumn{2}{c|}{ MULHERES } \\
\cline { 3 - 6 } & 24 & 11 & $45)$ & (f) & $(\%)$ \\
\hline Centro & 48 & 8 & 16,7 & 13 & 54,2 \\
\hline Norte & 46 & 9 & 16,1 & 40 & 83,3 \\
\hline Sul & 39 & 7 & 17,9 & 32 & 83,9 \\
\hline Leste & 27 & 11 & 40,7 & 16 & 82,1 \\
\hline Continente & 194 & 46 & 23,7 & 148 & 76,3 \\
\hline TOTAL & & \multicolumn{2}{|c}{} \\
\hline
\end{tabular}

Fonte: autoria própria (2014). f: frequência; \%: percentual.

Foram convidados a participar da pesquisa todos os indivíduos do sexo masculino que atenderam aos seguintes critérios de inclusão: ter 60 anos ou mais de idade (permitindo caracterizá-los como idosos do ponto de vista legal, nos países em desenvolvimento, tal qual o Brasil, conforme a OMS); integrar um dos grupos há, pelo menos, um mês; e estar frequentando os encontros do GCI no período de coleta de dados. Atenderam aos critérios de inclusão 38 homens idosos (10 do GCI - Centro; 6 do Norte; 8 do Sul; 5 do Leste; e 9 do Continente), sendo que todos aceitaram participar voluntariamente deste estudo. A média de idade desses 38 homens foi de $69,6 \pm 13,4$ anos.

É necessário relatar que outros dois homens (um do GCI - Continente e um do GCI- Sul), também atenderam aos critérios estabelecidos para participar da pesquisa. Contudo, pelo fato de um deles depender de equipamentos respiratórios que impossibilitavam sua fala, e de outro apresentar deficiência intelectual com dificuldade de comunicação, não foram incluídos no estudo, visto que não apresentavam condições de participar da entrevista. 
Para a melhor compreensão das realidades estudadas, torna-se relevante descrever algumas das principais características destes GCI: foram criados na década de 1990, com exceção do GCI - Leste, fundado em 2005. Os GCI - Centro e GCI Continente são formados exclusivamente por casais e foram criados com auxílio de instituições privadas, sendo que o primeiro ainda mantém esse auxílio, tendo sido idealizado por uma fundação voltada ao atendimento de bancários aposentados. Os cinco GCI recebem apoio da PMF, destacando-se o fornecimento mensal de um kit lanche (contendo alimentos como café, açúcar, leite, sucos industrializados, óleo, farinha de trigo, gordura vegetal, doce de leite e biscoitos doces e salgados).

Os encontros ocorrem semanalmente em quatro grupos (Centro, Norte, Sul e Leste), sendo que os participantes dos GCI - Norte, GCI - Sul e GCI - Leste reúnem-se no período vespertino. No GCI - Centro, os integrantes realizam suas atividades nos períodos vespertino e noturno. O GCI - Continente, por sua vez, realiza seus encontros quinzenalmente, nos períodos matutino e vespertino.

A diretoria é formada pelos próprios participantes dos grupos, não havendo profissionais de qualquer área conduzindo as atividades. Nos cinco GCI, há ao menos um coordenador, um vice-coordenador, um tesoureiro e um secretário. Os representantes são eleitos por meio de votação. Nos dois GCI formados por casais (Centro e Continente), a direção é exercida por um participante do sexo masculino, enquanto nos demais GCI (Norte, Sul e Leste), a coordenação é representada por uma integrante do sexo feminino. Mesmo que todos os GCI sejam destinados a idosos, há alguns membros com menos de 60 anos de idade, os quais desempenham, principalmente, a função de voluntários. 
As características dos GCI ora descritas foram identificadas durante o trabalho de campo, o qual foi iniciado após a aprovação desta investigação pelo Comitê de Ética em Pesquisa Envolvendo Seres Humanos da Universidade do Estado de Santa Catarina (parecer $n^{\circ} .701 .064$ de 26/06/2014). Assim, a coleta de dados compreendeu os meses de julho, agosto e setembro de 2014.

Os dados foram obtidos por meio da combinação de entrevistas e observações. A técnica de observação, empregada como instrumento de coleta de dados, caracterizou-se como sistemática, não participante e realizada no contexto real de presença do fenômeno (LAKATOS; MARCONI, 2007). Optou-se por uma matriz de observação organizada em um quadro representando alguns temas da pesquisa (aqui, especialmente, os conteúdos culturais do lazer desenvolvidos nos GCI), mas permitindo liberdade à pesquisadora nas anotações e também para registros complementares externos a esse quadro, realizados em um diário de campo (GIL, 2008).

As observações ocorreram durante quatro encontros consecutivos de cada um dos cinco GCI. Após esse período, os homens que atenderam aos critérios de inclusão estabelecidos foram convidados a participar individualmente de uma entrevista, nos mesmos dias e locais de encontro de cada GCI, porém, em um espaço reservado. Todos os entrevistados assinaram um Termo de Consentimento Livre e Esclarecido.

Tal entrevista foi elaborada por meio de um roteiro semiestruturado (MINAYO, 2012), constituído por questões básicas que permitiram complementar a identificação das atividades desenvolvidas nos GCI, bem como explorar a satisfação dos homens com essas atividades (O que o senhor mais gosta neste grupo? Por quê? / O que o senhor menos gosta neste grupo? Por quê? / O que não tem neste grupo que o senhor gostaria que tivesse?). Esse roteiro também foi constituído por algumas perguntas para 
caracterização dos participantes, tais como data de nascimento, escolaridade, profissão, entre outras. Para o registro das entrevistas foi utilizado um aplicativo gravador de áudio instalado no celular da pesquisadora principal.

Os depoimentos dos participantes foram transcritos na íntegra pela mesma pesquisadora, e cada entrevistado recebeu um nome fictício. Na sequência, as transcrições foram editadas conforme orientações de Duarte (2004), corrigindo-se, principalmente, repetições, vícios de linguagem e erros gramaticais. Além disso, foram inseridos colchetes no texto das transcrições quando se considerou necessário explicar o que, ou a quem, o participante estava se referindo. Por fim, as entrevistas transcritas foram entregues aos participantes para que eles pudessem alterá-las, caso julgassem necessário, a fim de validar seu conteúdo. Dois participantes solicitaram pequenos ajustes em suas entrevistas, sendo prontamente atendidos.

As informações coletadas foram tratadas por meio da técnica de análise de conteúdo categorial, na modalidade temática, seguindo as orientações de Bardin (2009). A análise categorial é empregada por meio de operações de desmembramento do texto em unidades e, seguidamente, em categorias. Estas são definidas como classes que reúnem grupos de elementos (unidades de registro) em razão de suas características comuns. As unidades de registros podem ser estabelecidas por critério semântico, ou seja, por temas. Neste caso, trata-se de uma análise de conteúdo na modalidade temática, consistindo em identificar os núcleos de sentido que compõem a comunicação (BARDIN, 2009).

A aplicação da técnica de análise em questão foi organizada em três etapas principais (BARDIN, 2009): 1) pré-análise (transcrição das entrevistas; digitação das informações registradas na matriz de observação sistemática e no diário de campo; 
organização dos dados; e leitura compreensiva, sendo possível identificar respostas e registros mais frequentes, assim como vislumbrar divergências e convergências); 2) exploração do material (análise propriamente dita, sendo codificadas unidades de registro (temas) em categorias de análise inicialmente estabelecidas para a pesquisa mais ampla - dentre as quais, estavam as categorias com resultados a serem apresentados neste estudo: conteúdos culturais do lazer desenvolvidos nos GCI, preferências e anseios por atividades no lazer); e 3) tratamento dos dados e interpretação (descrição dos resultados e inferência, atingindo os objetivos propostos).

Para a concretização dessas etapas, foram utilizados os recursos do software Qualitative Solutions Research NVivo, versão 9.2, especialmente no que se refere à organização e à codificação dos dados em categorias, bem como à classificação das fontes de acordo com as informações coletadas para a caracterização dos participantes.

\section{Resultados e Discussão}

Os seis conteúdos culturais do lazer - físicos, manuais, artísticos, intelectuais, sociais (DUMAZEDIER, 1980) e turísticos (CAMARGO, 1986) - foram observados dentre as atividades desenvolvidas nos cinco GCI investigados, alguns com maior predominância que outros, conforme será apresentado a seguir em subseções destinadas a cada conteúdo, ordenadas mediante tal predomínio. Dessa forma, tornou-se evidente que os GCI pesquisados contribuem para atender a esses interesses, em maior ou menor escala conforme cada grupo.

Gomes e Pinto (2009) ressaltam que cada atividade cultural está inscrita em uma trama de relações sociais, políticas, dentre outras que muito revelam sobre determinado contexto e sobre as pessoas que nele vivem. É possível concordar com as autoras que as 
manifestações culturais do lazer não podem ser entendidas isoladamente. Nesse sentido, na presente pesquisa, a análise dos conteúdos das vivências nos GCI não desconsiderou que em uma mesma atividade no lazer podem estar envolvidos diferentes interesses humanos. Porém, os conteúdos foram estabelecidos em termos de predominância, sendo discutidas inter-relações estabelecidas com outros, quando verificadas.

\section{O conteúdo turístico}

Da mesma forma com que foi verificado em outros estudos realizados em GCI de Florianópolis (SC) (ARAÚJO, 2004; BRAZ, 2008; LOPES, 2012), as atividades turísticas são frequentes nos cinco GCI investigados e se tornam tão atrativas aos idosos que influenciam, até mesmo, a dinâmica dos encontros semanais/quinzenais. Com exceção do GCI - Centro, as principais atividades desenvolvidas nos grupos (a exemplo dos bingos, das rifas, dos almoços) quase sempre são destinadas à arrecadação de recursos financeiros para a realização de passeios e de viagens, embora não se deva desconsiderar que tais atividades também acabam atendendo a outros interesses dos idosos. Além disso, os participantes contribuem com mensalidades a fim de viabilizar as viagens, principalmente.

Nos discursos dos homens idosos entrevistados, houve unanimidade em considerar as atividades turísticas como práticas que lhes geram muito prazer e satisfação. Inclusive, ao serem questionados sobre o que gostariam que tivesse no GCI que participam, muitos citaram mais passeios e viagens.

Nos GCI estudados, durante as reuniões, no processo de espera pela chegada do dia de passear/viajar, os homens idosos se mostraram ansiosos. Frequentemente, as conversas giravam em torno das próximas atividades turísticas, sendo que os esforços 
para conseguir dinheiro para o transporte, as refeições, a hospedagem, etc., tornavam-se ainda mais valiosos. Trata-se do imaginário, da primeira dimensão do turismo como atividade no lazer. Antecedendo a viagem, este é o domínio do sonho, do curtir a atividade por antecipação (MARCELLINO, 1996) ${ }^{4}$.

A segunda dimensão, que caracteriza a ação, o real, a vivência da viagem propriamente dita (MARCELLINO, 1996), não foi presenciada pela pesquisadora, mas os relatos dos participantes do estudo revelaram seu contentamento com a ruptura da rotina cotidiana, a descoberta do novo e com as relações sociais estabelecidas nesses períodos. Também, ao se reportarem aos momentos vividos durante essas atividades, demonstraram que elas não terminam quando acabam - caracterizando a dimensão da recordação (MARCELLINO, 1996) -, sendo prolongadas em seus pensamentos, os quais são compartilhados em conversas informais até mesmo com pessoas não muito próximas, tal qual a pesquisadora.

Tendo em conta que, frequentemente, os assuntos envolvendo o turismo são abordados por seus aspectos econômicos, sendo que as condições financeiras são vistas como principais limitantes para a vivência de atividades turísticas, considera-se importante, assim como Gomes, Pinheiro e Lacerda (2010), relativizar a ideia de que para vivenciar o lazer, por meio de seus diferentes conteúdos, é necessário dispor de muito dinheiro. O lazer precisa ter sentido para as pessoas que o usufruem, sendo necessário reconhecer, legitimar, incentivar e valorizar as iniciativas dos próprios indivíduos e da comunidade, assim como reconhecer o turismo como fenômeno sociocultural atrelado ao lazer.

\footnotetext{
${ }^{4}$ Baseando-se em trabalhos do sociólogo Paulo Salles Oliveira, Marcellino (1996) apresentou três dimensões envolvidas nas atividades turísticas (imaginação, ação e recordação), aqui observadas e descritas na interpretação dos dados da pesquisa envolvendo o conteúdo turístico.
} 
Sob essa ótica, as atividades turísticas tanto podem oportunizar a descoberta do novo e o enriquecimento das sensibilidades de forma crítica e criativa, quanto podem se constituir em simples ocasião de consumo conformista, representando meramente a fuga de problemas ou a reposição de energias. Como direito social (BRASIL, 1988), importa que as vivências turísticas também integrem a vida cotidiana dos idosos no lazer (GOMES; PINHEIRO; LACERDA, 2010; MARCELLINO, 1996). Nesse sentido, os GCI estão se apresentando como possibilidades férteis para o atendimento dos interesses turísticos dos homens investigados.

Deve-se ressaltar que viver o lazer por meio do turismo também pode aumentar consideravelmente o processo de integração entre os idosos e destes com as demais faixas etárias e lugares (GOMES; PINHEIRO; LACERDA, 2010). A inter-relação do conteúdo turístico com outros conteúdos culturais do lazer é muito clara (MARCELLINO, 1996), porém, neste estudo, o conteúdo social se destacou nessa interação, visto que é especialmente durante as viagens que surgem momentos de união, de conflitos, de tensões, de benevolência, os quais se configuram como possibilidade de estreitamento, aperfeiçoamento ou reflexão sobre as relações interpessoais.

Em um dos encontros observados no GCI - Continente, por exemplo, os participantes discutiram sobre um desentendimento ocorrido entre alguns integrantes do grupo durante o último passeio realizado. De acordo com os relatos, a rota do ônibus foi alterada pelo motorista a pedido de um dos homens participantes deste GCI, mas sem o conhecimento de todos e a anuência do coordenador. Pelo fato de o novo trajeto ter muitos aclives, algumas idosas passaram mal, gerando conflitos entre elas e o solicitador da mudança do trajeto. De qualquer modo, tal situação possibilitou a 
reflexão e o debate sobre as interações pessoais. Conforme depoimento do homem envolvido neste acontecimento:

[...] É um grupo amigo. [...] A gente está envolvido e eles têm consideração pela gente. Apesar do que acontece, mas é coisa que quem vive em grupo está sujeito a tudo. E não só sujeito a tudo, tem que relevar algumas coisas e, às vezes, não absorver outras. Foi o que aconteceu naquilo ali [referindo-se à discussão relatada anteriormente], onde fui obrigado a dar a mão à palmatória e depois fui obrigado a agir do meu jeito. Depois, todo mundo ficou do meu lado. Eu errei, mas fazer o quê? Acontece. [...] (Zilton, GCI Continente).

O espaço das relações humanas tem significados próprios, sendo constituído por elementos inerentes a cada pessoa, voltados ao lado introspectivo das emoções e sensações, provocando, muitas vezes, um estado de êxtase no contexto do espaço/ambiente no qual as pessoas estão situadas. Esse espaço/ambiente pode ser qualquer lugar (inclusive, trajetos de viagens), tornando-se equipamentos de lazer por excelência que propiciam interações entre as pessoas (STUCCHI, 1997). Claro que nem sempre essas relações são positivas e satisfatórias, mas caracterizam possibilidades de desenvolvimento de interações sociais. Nessa direção, enfatiza-se a importância dos interesses sociais do lazer, foco a seguir.

\section{O conteúdo social}

Foi observado em todos os grupos, seja na inter-relação com os demais conteúdos culturais, por meio da vivência de atividades que atendem prioritariamente a outros interesses humanos, mas nas quais também são evidentes as possibilidades de relações sociais (a exemplo das viagens, discutidas anteriormente); seja por meio de atividades sociais específicas, em que os relacionamentos constituem a única motivação. 
Britto da Motta (1999) acredita que, no fim das contas, todos os grupos de idosos acabam se constituindo em espaços privilegiados para o exercício da sociabilidade, à vista da sua característica de encontro/conflito/assimilação/negação de ideias, opiniões, hábitos, costumes, valores, estilos de vida, na convivência com outros idosos.

É possível concordar com a autora supracitada, afinal, o próprio processo de idealização e criação desses grupos perpassou pelo pressuposto da possibilidade de convivência e de relações sociais entre os participantes (ROLLIN, 1998). Sendo assim, a sociabilidade é frequentemente observada por estudiosos que investigaram GCI em diferentes cidades brasileiras (ARAÚJO, 2004; KIST, 2011; VARGAS; PORTELLA, 2013).

Dentre as atividades com interesses eminentemente sociais foram recorrentes, nos cinco GCI aqui investigados, rodas de conversas descontraídas, formadas espontaneamente entre os participantes dos grupos (de sexos iguais ou diferentes), antes ou após o início de outra prática, ou, ainda, durante as refeições. Como forma pura de sociabilidade, conforme explica Simmel (2006), a conversa tem um fim em si mesma e é regida por leis próprias, sendo que o assunto é somente o suporte indispensável do estímulo para essa forma de interação. Logo que a discussão se torna objetiva é modificado o eixo de sua diretriz, destruindo seu caráter de entretenimento sociável e se constituindo em uma finalidade, deixando, assim, de atender ao conteúdo social por si só, o que não pareceu ocorrer nos GCI pesquisados.

O lanche realizado em todos os grupos (e que também é permeado por conversas) despertou significativa atenção da pesquisadora por se manifestar como um importante instante de partilha (de alimento, sensações, percepções), de estímulo aos sentidos (da visão, do paladar, do olfato...), e de manifestação do sensível, constituindo 
mais um aspecto considerável nas relações entre os idosos. De acordo com Simmel (2006), o comer e o beber caracterizam o meio de reunião (e frequentemente o único) que propicia a ligação entre pessoas e círculos mais heterogêneos.

Nos cinco GCI, é durante o momento do lanche que muitos participantes se aproximam, conversam, dão risadas e estabelecem relações afetuosas, indicando que embora os lanches, por si sós, sejam apreciados por eles, constituem um pano de fundo para as relações interpessoais. Homens que passaram a maior parte do tempo próximos de sua esposa/companheira (conforme observado principalmente nos GCI - Norte e GCI - Sul) lancham junto com elas, mas, em seguida, procuram outro homem ou outra mulher para conversar enquanto terminam sua refeição, em uma constante inquietação para se manterem ocupados, mas também para se relacionarem com o outro.

Nos grupos citados e no GCI - Continente, o momento do lanche ocorre após a principal atividade desenvolvida para ocupar a tarde (o bingo), sendo precedido por uma ou mais orações em coro ou cantadas por músicas religiosas. No GCI - Continente, as orações também precedem os almoços realizados nas reuniões e são repetidas em outro momento particular: no início de cada encontro, quando alguns participantes também compartilham leituras de mensagens religiosas ou de trechos bíblicos.

Mesmo que ocupem poucos momentos das reuniões nos GCI mencionados, as práticas religiosas se mostraram presentes nesses locais, sendo merecedoras de discussões e reflexões. $\mathrm{Na}$ fala de alguns homens idosos entrevistados, os momentos dos encontros que envolvem práticas religiosas ganham sentidos especiais, principalmente por suas características de aproximar as pessoas, fortificando o senso de coletividade. 
[...] Normalmente, no café, a gente se concentra, algumas vezes até dá uma discussãozinha, dá um disse me disse, isso tem em tudo quanto é lugar. Na hora que a gente vai fazer a refeição [...] a gente procura se reunir, dar a mão um para o outro, fazer uma oração, então é um momento de concentração que eu acho muito bonito. Por isso que eu gosto [...] (Fabiano, GCI - Sul).

Foi possível observar a manifestação da religiosidade (atrelada à religião católica) por meio de orações, cantos, mensagens e leituras religiosas, mas, também, por meio de uma festa de adoração a santos (particularmente no GCI - Sul), neste caso, da popularmente conhecida Festa Julina. Apesar de a festa, por si só, atender aos interesses sociais do lazer, e também a outros (como artísticos e físicos), e de o aspecto religioso poder se configurar como mais um pretexto para a concretização da festa, não se deve ignorar as inter-relações estabelecidas entre o lazer e a religiosidade.

Gabriel e Marcellino (2007), ao discutirem lazer e religião, explicam que a aproximação de duas temáticas tão polêmicas como essas pode se dar por diferentes caminhos: para algumas concepções religiosas, a convivência entre as duas é possível com certas restrições; para outras, há uma enorme oposição entre ambas, uma vez que uma ameaça o tempo dedicado à outra; e, ainda, há a possibilidade da relação plena, harmônica e necessária entre lazer e religião. Em que se pese essa antinomia, os autores consideram preponderante a aproximação da teoria do lazer com a teologia no processo de superação de ranços de dogmatismos tradicionais limitadores de uma relação possível entre as duas temáticas. Além disso, ressaltam que ambas buscam uma nova síntese comprometida com a vida e estão a serviço da dignidade humana.

A religião, entendida tanto em suas práticas formais, quanto em práticas e dinâmicas que caracterizam a religiosidade (sem necessariamente estarem institucionalizadas), age de maneira determinante na forma como o lazer se concretiza. Entretanto, o inverso também é verdadeiro, ou seja, o lazer pode gerar valores que 
questionem ou legitimem determinadas práticas religiosas. Espera-se, com esses apontamentos, demonstrar que o lazer deve ser entendido em toda a sua complexidade (GABRIEL; MARCELLINO, 2007), considerando-se, por ora, suas relações com a religiosidade dos homens idosos participantes deste estudo, expressa por meio das práticas observadas nos GCI que eles integram.

O GCI - Centro foi o único em que não foram observados momentos com práticas religiosas, sendo difícil afirmar o porquê desta peculiaridade, mas, quiçá, de alguma forma, relacioná-la à estrutura de organização e ao processo de criação se diferir bastante dos demais grupos pesquisados. No GCI em questão, ainda, os lanches são dispostos em uma mesa central, não havendo um período específico para todos lancharem juntos, como verificado nos outros grupos. Não obstante, é comum haver idas e vindas à mesa que logo se transformam em pequenos grupos de conversas ao redor dela, mostrando que, embora aqui não haja (a priori) a característica coletiva das refeições, elas mesmas, por si só, facilitam pontos de encontros e aproximam os participantes, inclusive aqueles homens que ocupavam espaços mais reservados praticando alguma atividade individualmente.

Os depoimentos dos entrevistados mostraram que os momentos de refeições coletivas e de conversas com seus pares constituem uma das vivências nos GCI mais apreciadas por eles. Esses resultados elucidam a existência de uma carência, ou até de uma busca, por parte de um segmento etário/existencial que perdeu seu lugar social e ensaia construir algum outro. Seja a partir de uma necessidade de realização adicional ao seu itinerário de vida, ou, ainda, da procura por companhia ou pelo preenchimento do tempo (BRITTO DA MOTTA, 1999), a possibilidade de se relacionar com o outro vai se configurando de tal forma que assume tamanha percepção de satisfação, 
transcendendo simples modos de sociação e caracterizando aquilo que Simmel (2006) denominou de forma "pura" de sociabilidade, ou seja, quando o que predomina nas relações é somente o sentimento prazeroso por estar socializado.

[...] Eu também gosto muito da hora do café. É legal, todo mundo dá as mãos; todo mundo canta; se abraça. Quando a gente vai embora a gente se abraça, se beija. Isso eu acho uma coisa muito importante. [...] (Osni, GCI - Leste).

A oportunidade de relação entre os idosos também ocorreu durante os bingos, os quais integram as atividades de todos os grupos, a exceção do GCI - Centro. Os contatos interpessoais e os diferentes elementos sociais estabelecidos nesse jogo, que permitiram caracterizá-lo como uma atividade de interesse social, são muito mais arrebatadores aos olhos de quem aprecia de fora. Isso porque, apesar de ser uma atividade que tem a finalidade específica de arrecadar recursos financeiros para a realização dos passeios e das viagens, nos quatros GCI em que é ela desenvolvida, as observações revelaram importantes situações, nas quais os contatos face a face são privilegiados. Por exemplo: nas brincadeiras feitas entre os participantes durante o jogo; nas conversas, nos olhares, nos comentários trocados; nas risadas que surgem quando alguém "fura" uma rodada ou quando o cantador fala algo engraçado; na exposição do prêmio ganhado para o grande grupo; no modo diferenciado de gritar "bingo" ou avisar que ganhou; na forma de deslocamento do lugar onde o participante estava sentado até a mesa do cantador para conferência da cartela.

Nada obstante a essas características do bingo que atendem a interesses sociais, é preciso mencionar que nem todos os homens investigados apreciam essa atividade (talvez pelo fato de a maioria dos prêmios ser utensílios de cozinha e, até mesmo, roupas femininas; e/ou, por, nem sempre, poderem desenvolver outras atividades que 
gostariam, haja vista a determinação dos coordenadores para todos participarem deste jogo). Assim, alguns homens participam dessa vivência por não haver outras opções no grupo. É notória a supremacia do jogo de bingo, enraizado no cotidiano das reuniões de quatro entre os cinco GCI estudados, sendo esta uma característica recorrente em outros grupos da cidade de Florianópolis (SC) (ARAÚJO, 2004; LOPES, 2012).

No que se refere aos órgãos municipais responsáveis pela gestão desses GCI, documentos demonstram sugestões de atividades, e não intervenções, calcando-se no princípio de autonomia dos participantes para decidirem suas programações (PMF, 2014). Contudo, deve-se considerar a necessidade de educação para o lazer, que nem sempre foi possibilitada às pessoas. Em suma, a escolha, a opção, e a elaboração de uma programação, em termos de conteúdos culturais, estão diretamente ligadas ao conhecimento das alternativas que o lazer oferece e ao incentivo para a sua vivência (MARCELLINO, 2007).

De qualquer forma, torna-se evidente que os GCI se constituem em espaços férteis para o desfrute dos interesses sociais do lazer. Isso porque, mesmo em um GCI com maioria absoluta de participantes do sexo masculino, tal qual o grupo da cidade de Alegre (RS), investigado por Vargas e Portella (2013), o conteúdo social do lazer se sobressai. Os homens idosos investigados por esses autores perceberam as atividades realizadas no GCI, especialmente as sociais, como fatores determinantes para a participação no grupo e geradores de sensações de bem-estar e satisfação pessoal.

Diante do exposto, é preciso considerar, conforme Dumazedier (1980), que as relações interpessoais configuram-se como um campo específico de ambiguidades, contradições e conflitos entre interesses pessoais e sociais, podendo apresentar aspectos positivos e negativos para a coletividade e para o indivíduo. O desenvolvimento 
excessivo dos interesses pessoais pode dificultar o funcionamento de uma associação organizada. Por outro lado, as relações afetivas podem favorecer novas relações sociais, conforme verificado entre os dados do presente estudo, visto que os homens investigados relataram desenvolver estas relações com outros integrantes dos GCI.

\section{O conteúdo intelectual}

Este conteúdo manifestou-se em quatro GCI (Centro, Continente, Leste e Sul), principalmente por meio de leituras e jogos. As leituras apareceram nos GCI do Centro e do Continente, mas não nos demais grupos, podendo estar associadas às diferenças entre os níveis de escolaridade constatados entre os homens. Nesses dois GCI, a maior parte deles tem ensino médio ou superior, enquanto, nos outros grupos (Leste, Sul e Norte), muitos informaram ter tido de um a quatro anos de estudo, e, em consequência disso, apresentarem dificuldades de leitura e escrita.

Quando propôs a classificação dos interesses culturais do lazer, Dumazedier (1980) já alertava que os conteúdos intelectuais, juntamente com os artísticos e os sociais, são os mais sensíveis às diferenças de classes sociais e profissionais. Nessa direção, ao discutir a leitura como forma de prazer e informação para poucos, Marcellino (1996), além de relembrar a existência de índices de baixa alfabetização brasileira, apresentou outros fatores que dificultam a formação do gosto pela leitura como atividade no lazer, tal qual o caráter de ensino da língua como simples instrumento do desenvolvimento cognitivo. Para ele, é preciso que o estímulo à fala, aliado à capacidade de leitura e de escrita, sejam também incentivados como forma de atendimento de necessidades humanas que podem ser geradoras de prazer, privilegiadamente nos momentos de lazer. 
No GCI - Centro, foram observadas atividades individuais de leitura de livros, jornais e revistas, geralmente desenvolvidas pelos mesmos dois homens idosos em um espaço reservado, enquanto no GCI - Continente, foi verificada uma atividade sistemática de compartilhamento de informações e conhecimentos com os integrantes do grupo, denominada por eles como "momento literário". Essa atividade ocorre pela manhã, durante a reunião de abertura do encontro deste grupo. Espontaneamente, algumas pessoas leem para o grupo alguma mensagem (religiosa ou não), piada, notícia ou informação trazida de casa, veiculada pelos meios de comunicação de massa ou disponíveis em livros, revistas, etc.

No GCI - Centro, ainda, destaca-se a presença de uma televisão que, embora seja mantida ligada a maior parte do tempo dos encontros do grupo (possivelmente por um hábito construído a partir da supremacia desse meio de comunicação), não prende a atenção dos participantes. Os homens desviam a atenção das atividades que estão desenvolvendo apenas no momento dos noticiários, quando, às vezes, passam a conversar sobre os assuntos veiculados.

O conteúdo intelectual também foi evidenciado em jogos de cartas e de dominó, desenvolvidos tanto nos GCI do Centro e do Continente, quanto nos GCI - Leste e GCI - Sul. Particularmente no GCI - Centro, esses jogos ocupam quase todo o tempo das reuniões do grupo. Embora algumas mulheres também joguem (especificamente cartas), elas se apropriam de um local distante dos homens e geralmente formam parcerias entre elas mesmas. Isso significa que, apesar de homens e mulheres apreciarem jogos de cartas, cada qual prefere desenvolvê-las entre seus pares do mesmo sexo, repercutindo em atitudes e comportamentos que, de certa forma, reproduzem estereótipos esperados para cada sexo e uma separação, advinda de questões culturais, que, possivelmente, 
ocorreu durante toda a vida, atribuindo papéis específicos para o homem e para a mulher.

No "lado dos homens", o silêncio predomina a maior parte do tempo, indicando concentração e atenção às regras e estratégias do jogo. Alguns comentários são tecidos, mas se referem principalmente ao próprio jogo. Eventualmente, emergem risadas e conversas sobre outros assuntos (como futebol, política, etc.), revelando interações com os conteúdos sociais, mas essas não se sobressaem.

No estudo de Coutinho e Acosta (2009) - desenvolvido no contexto de três clubes da cidade de Santa Maria (RS) frequentados quase que exclusivamente por homens - também foi observada a presença marcante do silêncio no comportamento de homens idosos durante jogos de cartas. Os autores salientam que essas atividades parecem despertar mais o interesse deles, tendo em vista que muitos convidam suas esposas para frequentar tais clubes, mas elas não participam por considerar não haver práticas de seu interesse.

No presente estudo, no contexto do GCI - Continente, a preferência é pelo dominó e não é comum as mulheres participarem, seja junto com os homens ou apenas entre elas. Os homens também se organizam voluntariamente, havendo repetição de duplas e apropriação de um espaço mais reservado com risadas e conversas esporádicas, e observadores constantes.

No GCI - Leste, embora demonstrem e afirmem gostar bastante, os homens costumam jogar dominó apenas enquanto a principal atividade do grupo (o bingo) não começa, em virtude de esta última já estar instituída como integrante de todos os encontros. Em contrapartida, no GCI - Sul, o jogo de dominó foi observado em alguns 
encontros somente entre mulheres, também antes do início do bingo ou durante uma reunião, na qual estava sendo promovida uma festa e não houve este último jogo.

Frente ao exposto, constatam-se preferências, quanto aos interesses intelectuais, similares e diferentes entre os homens idosos entrevistados, conforme cada GCI. Além disso, em alguns casos, foram observados tanto homens quanto mulheres desenvolvendo os mesmos tipos de atividades intelectuais, contrariando os estereótipos que apresentam certas atividades no lazer como femininas ou masculinas (GOELLNER et al., 2009). Scott (2005) lembra que os indivíduos não são iguais. Suas desigualdades repousam em diferenças presumidas entre eles, as quais não são singularmente individualizadas, mas tomadas como sendo categóricas. Assim, a identidade de grupo é o resultado dessas distinções categóricas atribuídas, sendo que sua aceitação ou rejeição está amparada na negação e na reprodução de determinados estereótipos, nas demandas pela igualdade nas relações de gênero.

\section{O conteúdo manual}

Os interesses manuais manifestaram-se, principalmente, nos GCI - Centro e GCI - Leste por meio de atividades envolvendo corte e costura (porém, essas desenvolvidas exclusivamente por mulheres), em ambos os grupos, assim como constatado em estudos anteriormente realizados em GCI da cidade (ARAÚJO, 2004; LOPES, 2012); e de confecção de redes de pesca, no segundo grupo (desenvolvidas apenas por homens). Esta atividade ainda não havia sido apontada entre outros estudos realizados em GCI de Florianópolis (SC) (ao menos entre os aqui referenciados). Neste caso, parece haver uma relação com a atividade profissional desempenhada pelos homens do GCI - Leste. 
Todos os homens entrevistados desse GCI exemplificaram a pesca como atividade que, em algum ou em todos os momentos de suas vidas, caracterizou sua tarefa laboral. Assim, a confecção de redes já fazia parte da rotina de atividades dessa profissão. Agora, em um processo de deslocamento da pesca do âmbito do trabalho para a esfera do lazer, a prática da confecção de redes, conforme seus depoimentos, é determinada eminentemente pela satisfação proporcionada. Em contrapartida, sua inclusão no GCI - Leste, assim como das demais atividades manuais citadas (desenvolvidas pelas mulheres), tem finalidades específicas, como utilizar os materiais confeccionados para os prêmios dos bingos e das rifas, com o intuito de arrecadar recursos para as atividades turísticas. Os participantes recebem os materiais comprados pela direção do grupo e desenvolvem essas atividades em casa ou nas reuniões do GCI, antes do início da principal atividade (o bingo).

Em ambos os casos, tendo em vista a sutil proximidade entre divertimento e obrigação, alguns autores poderiam considerar os exemplos de atividades manuais citados como "semilazer", tendo em vista suas finalidades lucrativas ou utilitárias (DUMAZEDIER, 1980). Conforme lembram Melo e Alves Júnior (2012), muitas vezes, em virtude de sua natureza, as atividades manuais são confundidas com trabalho. Mesmo quando em sua origem se constituem em atividades no lazer, em decorrência de necessidade econômica ou da opção por uma renda suplementar, podem se tornar laborais, não permitindo sua consideração como vivências no lazer propriamente ditas.

Ainda sobre as atividades manuais, é relevante informar que dois homens gostariam que esse conteúdo fosse desenvolvido no espaço dos GCI que frequentam, indicando que o sexo masculino também pode se interessar por tais atividades: 
O que eu vejo nos outros grupos é que o pessoal faz oficina. Aqui é só isso: o joguinho de bingo e o café colonial como tem toda tarde. Mas, eu queria que o pessoal aqui participasse mais de eventos. Tem grupo que tem oficina de bordado, outros jogam vôlei. [...] Se tivesse isso seria muito bom. Mudava a rotina (Márcio, GCI - Norte).

Quando eu cheguei aqui ainda peguei um comecinho de essas mulheres trabalhando, fazendo aquele artesanato [...]. Eu até disse: "vou para lá agora, eu sei fazer tarrafa... Faço tarrafa". Mas, parece que foi só eu chegar e acabaram com isso. Isso eu gostaria que tivesse (Alisson, GCI - Sul).

Como hobby, nova forma de estímulo ou possibilidade de desenvolvimento das habilidades pessoais, as atividades manuais constituem-se em uma importante opção para o tempo disponível (MARCELLINO, 1996). No contexto dos GCI pesquisados, apesar de, muitas vezes, essas atividades terem finalidades específicas, os homens idosos também demonstraram seu gosto por praticá-las.

\section{O conteúdo artístico}

Atividades com interesses artísticos ocupam poucos momentos dos encontros de quatro GCI investigados, não tendo sido observadas no GCI - Norte. Contudo, no GCI Centro, esses interesses se manifestaram apenas entre algumas mulheres que assistiriam a novelas na televisão. Os homens não demonstram interesse por essa vivência no grupo mencionado.

No GCI - Sul, a realização de uma Festa Julina atendeu a interesses artísticos ao ser verificado o prazer com que muitos homens idosos cantavam, desfrutavam das músicas, contemplavam as danças e se organizavam para formar coreografias, dançando em rodas constituídas por pequenos grupos. Alguns deles, inclusive, estavam trajados a rigor (com camisa xadrez e chapéu de palha na cabeça), embelezando o cenário do 
espetáculo. O salão também estava decorado com bandeirolas, típicas desse tipo de festa.

De acordo com Rosa (2007), há diferentes formas de participação em uma festa (observando, dançando, conversando, etc.) e variados elementos que a compõem, tais como crendices, gestualidades, costumes, valores, corpos, religiosidades, tradições, danças, cores, adornos, divertimentos, ritos, celebrações, músicas. Permeada por renúncias, coexistências e conflitos, a festa possibilita interpenetrações de culturas diversas, conforme a mesma autora. Nesse contexto, embora a dança incluída na festa também atenda a interesses físicos, o que se destaca, neste momento, é a experiência artística/estética mais ampla.

No GCI - Leste, embora não tenha sido presenciada nenhuma festa ou a realização de outras atividades que atendessem prioritariamente aos interesses artísticos, as entrevistas de dois homens revelaram momentos vivenciados pelo grupo (especialmente em viagens ou em festas organizadas para arrecadação de recursos que viabilizem as primeiras), nos quais o conteúdo artístico manifestou-se por meio do canto; do tocar instrumentos musicais; e da organização da festa como espetáculo.

No GCI - Continente, os discursos de alguns homens também mostraram que o conteúdo artístico se manifesta durante momentos em grupo externos ao local físico em que se encontram quinzenalmente, como nas viagens. Por outro lado, os interesses artísticos são atendidos nas reuniões quinzenais do grupo durante o canto do hino, particularmente no instante de abertura dos encontros. As emoções transbordam durante essa atividade, despertando, entre os participantes, aplausos, lágrimas e comentários como "está cada dia mais bonito". 
O canto é regido por um homem idoso que atuou como músico da banda da polícia militar em sua vida profissional. É do discurso dele que emerge a verificação do conteúdo artístico durante as viagens e também a vontade de que o canto e o tocar instrumentos integrassem mais as atividades deste grupo.

[...] Nós tínhamos antes no grupo um coral. Eu é que era o regente do coral. Teve um tempo aqui que a gente saía e tocava quando chegava à frente dos hotéis. Hoje ainda nós fizemos, mas naquele tempo tinham mais componentes, mais instrumentos, então nós tocávamos na entrada do hotel e na saída também. [...] Se aparecessem mais uns dois ou três idosos que tocassem algum instrumento, aí nós formávamos um coral. Ficaria melhor ainda (Patrício, GCI - Continente).

Para além desse momento dedicado exclusivamente ao canto, as observações revelaram outras situações, nas quais os participantes do GCI em questão também vivenciam essa atividade. Por exemplo: durante determinado encontro, após o almoço, enquanto o bingo não iniciava, homens e mulheres se reuniram em uma mesa para cantarem juntos músicas diversas.

Os momentos de lazer concretizados por meio do cantar, do festar e do tocar instrumentos musicais vão de encontro ao crescimento do consumo em detrimento da prática, apontado por Marcellino (1983) como processo atrelado à expansão da indústria cultural. Tal processo contribuiu para a desvalorização das atividades pela satisfação que proporcionam ao passo da busca por níveis mais elevados de perfeição e da competição. Os tipos de vivências artísticas identificados no contexto dos GCI pesquisados no presente estudo reafirmam a necessidade de reflexão sobre esse conteúdo cultural, o qual, segundo Melo e Alves Júnior (2012), pode despertar diferentes sensibilidades para que se tenha acesso a novos valores ou ao questionamento dos valores vigentes. 
Há de se explicitar que todas as pessoas podem produzir suas manifestações artísticas, independentemente de seu grau de habilidade, pois a arte não é privilégio de virtuoses, como muitos acreditam. É preciso contestar e combater a visão, que, ainda hoje, impera na população em geral, de que somente quando se fala de arte está também se referindo à cultura, indicando um grupo particular de manifestações relacionadas à cultura erudita, acessíveis a uma minoria social favorecida que possui educação para buscar a arte em seus momentos de lazer (MELO, 2007; MELO; ALVES JÚNIOR, 2012).

Desta forma, não basta que se informe de fora o que é, ou não, arte; é preciso pensar em quanto e como as pessoas sentem, ou não, uma determinada vivência como tal (MELO, 2002). Conforme Melo (2007), as pessoas precisam descobrir as diferentes linguagens humanas, aumentando seu grau de interação e criando mais possibilidades para que possam exercer seu direito de seleção e escolha, especialmente a partir do desenvolvimento de novos olhares, sentidos, signos, símbolos, sentimentos e sensibilidades. A arte urge ser explorada em suas diversas dimensões, incorporando-se nas opções de lazer das pessoas, tendo em vista o potencial estético e de estímulo ao desenvolvimento das sensibilidades que ela pode desencadear, os quais podem implicar em novas formas de contato com a realidade.

\section{O conteúdo físico}

Foi possível observar o conteúdo físico apenas em um dos encontros do GCI Sul, presenciado pela pesquisadora. A dança, como parte integrante de uma festa, apresentou-se como possibilidade de atender ao interesse de movimentação corporal. 
Mesmo relatando sentir dores e ter limitações físicas, ficou claro o prazer que os homens sentem por se exercitar por meio da dança:

[...] Quem dança, dança. Quem não dança, olha... Como eu, por exemplo, que já estou enferrujado, dói o joelho... Então, eu fico olhando e é uma diversão (Fabiano, GCI - Sul).

Interessante mencionar que a dança é um dos principais exemplos de atividade física caracterizada na cultura como prática feminina. Ainda que no senso comum essa seja uma ideia assumida como "natural", ela não está desprovida de um caráter discriminatório e preconceituoso, evidenciando, de certo modo, o tratamento diferenciado que a sociedade atribui aos distintos grupos que a compõem. No curso da história, homens e mulheres foram educados praticando exercícios diferentes. Dessa forma, o que era aconselhado para os homens não correspondia ao que as mulheres deveriam realizar. Tal separação, baseada na biologia dos corpos, terminou por se engendrar na cultura brasileira, determinando o que é masculino e o que é feminino em termos de atividades físicas (GOELLNER et al., 2009).

Em uma pesquisa realizada em um projeto social de esporte e lazer na cidade do Rio de Janeiro (RJ), por exemplo, durante aulas de dança de salão com predominância de mulheres, um dos poucos homens presentes disse aos pesquisadores que sofre preconceito dos amigos por participar dessa atividade, a qual, para seus amigos, é "coisa de mulherzinha" (GOELLNER et al., 2010).

Determinações como essas precisam ser analisadas e questionadas, identificando e desqualificando os estereótipos que estabelecem papéis e funções específicas para homens e para mulheres (GOELLNER et al., 2009). Conforme verificado neste estudo, uma atividade tradicionalmente feminina pode trazer tanto prazer aos homens quanto 
traz às mulheres, sem necessariamente estabelecer opções sexuais.

No GCI - Leste, a dança também foi mencionada como integrante de festas, contudo, diferentemente do GCI - Sul, as festas têm a finalidade de arrecadar recursos financeiros para passeios e viagens, sendo oportunizada poucas vezes ao longo do ano e sempre em outros locais que não o de encontro habitual do grupo, pela necessidade de comportar uma quantidade maior de pessoas. Além disso, em algumas viagens e passeios, conforme depoimentos dos homens entrevistados, determinados bailes são visitados pelos participantes para dançarem, reafirmando o apreço que eles têm por essa atividade.

Com exceção dos homens idosos do GCI - Centro, a maioria dos homens entrevistados nos demais grupos pesquisados informou que gostaria que atividades físicas fossem incluídas nos encontros, principalmente a ginástica e a dança:

[...] Uma das coisas que eu acho que deveria ter aqui, mas a maioria não vai fazer, uma atividade, uma ginástica, tipo ginástica laboral. Antes de começar as coisas, tirar o grupo para o pessoal se esticar, fazer um alongamento. Mas, se tiver, $90 \%$ não participam porque acham que são velhos, que já não conseguem. É uma coisa que estimula. Acho que é uma coisa que deveria ter (João, GCI Continente).

Curioso que, em outros GCI de Florianópolis (SC), com presença ainda menos expressiva de homens do que nos cinco GCI aqui investigados, conforme estudos desenvolvidos por outros pesquisadores (ARAÚJO, 2004; BRAZ, 2008; LOPES, 2012), atividades como dança e ginástica parecem ser mais frequentemente desenvolvidas nesses espaços e um dos motivos apontados nesses trabalhos para a baixa participação masculina é não haver atividades de interesse dos homens. Nos cinco GCI ora analisados, os homens não só exprimem seu gosto por tais atividades e participam delas 
quando são realizadas (particularmente, a dança), como também clamam por sua inserção nos grupos que frequentam e afirmam praticá-las fora desses espaços.

Isso ratifica a ideia de que, nas atividades tidas como "de mulheres", também pode haver (e há) participação de homens, inclusive no segmento populacional de idosos. Goellner et al. (2010) também observaram essa situação ao analisarem um programa de caminhada desenvolvido em Porto Alegre (RS): homens e mulheres participavam das atividades na mesma proporção, sendo semelhantes a frequência de participação e os aspectos motivacionais para participar, em ambos os sexos.

Desse modo, na caminhada, na ginástica, na dança, e nas diversas possibilidades de atividades físicas no lazer, são formados modos plurais de viver e de produzir feminilidades e masculinidades. Os estudos sobre masculinidades ainda são incipientes, sendo que aqueles existentes estão direcionados a uma masculinidade hegemônica, na qual atributos viris são reconhecidos e incentivados. Portanto, há de se analisar outros modos de ser masculino no contexto de atividades físicas tradicionalmente associadas a práticas femininas (GOELLNER, 2013), pois não há como negar que as atividades físicas e os esportes estão entre as manifestações culturais mais procuradas pelas pessoas e mais difundidas pelos meios de comunicação de massa (MELO; ALVES JÚNIOR, 2012), havendo presença de homens nas atividades “femininas" e vice versa.

Os desafios dos profissionais de lazer, nesse cenário, estão, principalmente, em ampliar o acesso das pessoas a diferentes tipos de atividades físicas (MELO; ALVES JÚNIOR, 2012). É perceptível ao longo da história, por exemplo, que no interior das propostas de realização de atividades físicas e esportivas, a prática tem privilegiado a quem pode pagar pelos serviços. Sem desconsiderar a necessidade de valorização dos 
Profissionais de Educação Física, essa situação muitas vezes se torna um critério excludente e restritivo à prática de atividades físicas (CARVALHO, 2001).

Neste estudo, nota-se que existem idosos querendo praticar atividades físicas e esportivas no lazer, mas que não têm acesso aos serviços de profissionais da área. Alguns homens idosos apontaram que a PMF viabilizou a prática orientada de atividade física nos grupos em outros momentos, e que gostariam que ela voltasse a integrar o cotidiano dos encontros:

Eu gostaria que tivesse uma [atividade] física. Por enquanto não tem. Este ano a Prefeitura ainda não deu. Até os outros anos tem dado, mas este não (Renan, GCI - Sul).

No GCI - Centro, conversas informais com os participantes revelaram que eles já custearam uma Profissional de Educação Física para orientar exercícios em alguns momentos dos encontros do grupo. Todavia, poucos homens participavam por manifestarem preferência pela prática de outras atividades nesse espaço, sendo que, por esse motivo, essa prática foi interrompida. Assim, neste GCI, foi identificado menor interesse por essas atividades, não significando que os homens integrantes deste e dos demais GCI investigados não tenham direito de acesso ao conteúdo físico do lazer, sugerindo, ao menos, a necessidade de reflexão sobre o assunto por parte dos órgãos municipais responsáveis por tais espaços.

\section{Considerações Finais}

Foi possível constatar que os homens idosos investigados neste estudo encontram oportunidades privilegiadas para atender aos interesses turísticos (por meio dos passeios e das viagens) e sociais do lazer (por meio dos bingos; dos momentos de 
refeições, acompanhado por orações em alguns grupos; e das conversas), no contexto dos cinco GCI analisados. As atividades turísticas são apreciadas por todos os homens entrevistados. Por outro lado, os bingos, como atividades sociais, não atendem às preferências de alguns homens integrantes dos quatro GCI em que esse jogo é realizado (Norte, Sul, Leste e Continente), talvez por ser uma atividade com alguns elementos de maior interesse das mulheres (a exemplo dos prêmios: roupas femininas, utensílios de cozinha, etc.).

No GCI - Norte, esses são os únicos conteúdos explorados no momento. Os homens integrantes deste grupo manifestaram interesse pela inclusão de atividades manuais e físicas nos encontros. Nos demais grupos (Centro, Sul, Leste e Continente), também existem possibilidades para atendimento dos interesses intelectuais e artísticos. O conteúdo intelectual foi identificado principalmente por meio de leituras nos GCI Centro e Continente, e por meio de jogos de cartas e/ou dominó, nesses dois grupos e também nos GCI - Leste e GCI - Sul. Contudo, neste último grupo, apenas mulheres foram observadas jogando, especificamente dominó. O conteúdo artístico, por sua vez, embora presente nesses quatro GCI, foi identificado com menor frequência, sendo oportunizado, principalmente, por meio de festas esporádicas realizadas nos GCI - Sul e GCI - Leste; por meio do canto e do tocar instrumentos, neste último grupo e no GCI Continente; e a partir de novelas no GCI - Centro, entretanto, esse tipo de programação é assistida apenas pelas mulheres deste grupo.

Da mesma forma, o conteúdo manual foi identificado nos GCI - Centro e GCI Leste por meio de atividades como corte e costura, mas essas são realizadas exclusivamente por mulheres. Neste último GCI, em contrapartida, há uma atividade manual desenvolvida apenas por homens (confecção de redes de pesca). 
O conteúdo físico, por fim, foi identificado no GCI - Sul, por meio da dança, como parte integrante de uma festa; e no GCI - Leste, a partir de relatos dos homens entrevistados, também por meio da dança. Com exceção do GCI - Centro, homens de quatro GCI investigados destacaram seu desejo pela inserção de atividades físicas nos encontros dos grupos que participam, tais como dança e ginástica.

Os conteúdos culturais do lazer identificados por meio das atividades observadas nos encontros e relatadas pelos homens idosos entrevistados, no contexto dos GCI estudados, podem servir como um diagnóstico preliminar sobre o assunto, impulsionador de discussões e de reflexões sobre o (não) atendimento de interesses humanos, especialmente de homens, no lazer concretizado nesses GCI. Para além disso, as percepções e reproduções por meio da fala dos homens acerca das aspirações por inovações na rotina de atividades dos GCI podem se configurar como um ponto de partida para a ampliação dos interesses culturais do lazer nesses espaços, na perspectiva dos homens idosos, visto que nem todos apreciam as práticas realizadas em sua totalidade. Além disso, o interesse por vivências no lazer consideradas socialmente como "femininas" pode auxiliar na desconstrução de estereótipos culturais sobre o assunto, oportunizando aos homens idosos o acesso a essas possibilidades de vivências culturais.

Considerando a lacuna na literatura científica nacional com a população aqui investigada, particularmente no que se refere às atividades vivenciadas no lazer, sugerese a ampliação desta pesquisa para outros GCI de Florianópolis (SC) e de outras cidades brasileiras. Novas investigações sobre o assunto poderão avançar nas limitações deste estudo (como o tempo de observações restrito a quatro encontros de cada GCI e a investigação direcionada aos GCI com representatividade de homens um pouco mais 
expressiva), trazendo informações que permitam aprofundar as discussões ora desenvolvidas.

\section{REFERÊNCIAS}

ARAÚJO, Vera Nícia Fortkamp. Os coordenadores de grupos de convivência de idosos como facilitadores da construção da cidadania. 2004. 116 f. Dissertação (Mestrado em Serviço Social) - Centro Socioeconômico, Universidade Federal de Santa Catarina, Florianópolis, 2004.

BARDIN, Laurence. Análise de conteúdo. Ed. rev. e atual. Lisboa: Edições 70, 2009.

BRASIL. Constituição (1988). Constituição da República Federativa do Brasil. Brasília, 2013. Disponível em: http://www.presidencia.gov.br/legislacao . Acesso em: 20 ago. 2013.

Lei no ${ }^{\mathbf{0}} \mathbf{8 . 8 4 2}$, de 4 de janeiro de 1994. Dispõe sobre a Política Nacional do Idoso, cria o Conselho Nacional do Idoso e dá outras providências. Diário Oficial [da] República Federativa do Brasil, Brasília, 1994.

BRAZ, Letícia Guimarães. Projeto viver bem a idade que se tem: um redimensionamento do trabalho social com idosos do SESC de Florianópolis. 2008. 108 f. Trabalho de Conclusão de Curso (Bacharelado em Serviço Social) - Centro Socioeconômico, Universidade Federal de Santa Catarina, Florianópolis, 2008.

BRITTO DA MOTTA, Alda. "Não tá morto quem peleia": a pedagogia inesperada nos grupos de idosos. 1999. 270 f. Tese (Doutorado em Educação) - Programa de PósGraduação em Educação, Faculdade de Educação, Universidade Federal da Bahia, Salvador, 1999.

BROD, Alessandra. Políticas públicas de lazer para os idosos na região do Vale do Taquari: um estudo descritivo dos grupos de convivência e bailes da terceira idade. 2004. 135 f. Dissertação (Mestrado em Ciências do Movimento Humano) - Escola de Educação Física, Universidade Federal do Rio Grande do Sul, Porto Alegre, 2004.

CAMARANO, Ana Amélia; KANSO, Solange; MELLO, Juliana Leitão. Como vive o idoso brasileiro? In: CAMARANO, Ana Amélia (Org.). Os novos idosos brasileiros: muito além dos 60? Rio de Janeiro: IPEA, 2004. p. 25-73.

CAMARGO, Luiz Octávio de Lima. O que é lazer. São Paulo: Brasiliense, 1986.

CARVALHO, Yara Maria. Atividade física e saúde: onde está e quem é o "sujeito" da relação? Revista Brasileira de Ciências do Esporte, Florianópolis, v. 22, n. 2, p. 9-21, jan. 2001. 
COUTINHO, Renato Xavier; ACOSTA, Marco Aurélio de Figueiredo. Ambientes masculinos da terceira idade. Ciência \& Saúde Coletiva, Rio de Janeiro, v. 14, n. 4, p. 1111-1118, jul./ago. 2009.

DUARTE, Rosália. Entrevistas em pesquisas qualitativas. Educar, Curitiba, n. 24, p. 213-225, 2004.

DUMAZEDIER, Joffre. Valores e conteúdos culturais do lazer. São Paulo: SESC, 1980.

GABRIEL, Oldrey Patrick Bittencourt; MARCELLINO, Nelson Carvalho. Algumas aproximações possíveis entre lazer e religião. Licere, Belo Horizonte, v. 10, n. 3, p. 122, dez. 2007.

GIL, Antônio Carlos. Métodos e técnicas de pesquisa social. 6. ed. São Paulo: Atlas, 2008.

GOELLNER, Silvana Vilodre et al. Gênero e Raça: inclusão no esporte e lazer. Porto Alegre: Ministério do Esporte / Gráfica da UFRGS, 2009.

; et al. Lazer e gênero nos programas de esporte e lazer das cidades. Licere, Belo Horizonte, v. 13, n. 2, p. 1-20, jun. 2010.

Gênero e esporte na historiografia brasileira: balanços e potencialidades. Tempo, v. 17, n. 34, p. 45-52, jan./jun. 2013.

Gênero. In: GOMES, Christianne Luce (Org.). Dicionário crítico do lazer. Belo Horizonte: Autêntica, 2004. p. 97-100.

GOMES, Christianne Luce. Significados de recreação e lazer no Brasil: reflexões a partir da análise de experiências institucionais (1926-1964). 2003. 322 f. Tese (Doutorado em Educação) - Faculdade de Educação Física, Universidade Federal de Minas Gerais, Belo Horizonte, 2003.

; PINHEIRO, Marcos; LACERDA, Leonardo. Lazer, turismo e inclusão social: intervenção com idosos. Belo Horizonte: UFMG, 2010.

; PINTO, Leila. O lazer no Brasil: analisando práticas culturais cotidianas, acadêmicas e políticas. In: GOMES, Christianne et al. (Org.) Lazer na América Latina. Belo Horizonte: UFMG, 2009. p. 67-122.

IBGE - INSTITUTO BRASILEIRO DE GEOGRAFIA E ESTATÍSTICA. Censo demográfico 2010: características da população e dos domicílios - Resultado do universo. Rio de Janeiro, 2011.

IBGE - INSTITUTO BRASILEIRO DE GEOGRAFIA E ESTATÍSTICA. Síntese de indicadores sociais: uma análise das condições de vida da população brasileira 2013. Rio de Janeiro, 2013. 
KIST, Rosane Bernardete Brochier. Os grupos de convivência em Porto Alegre e sua contribuição à garantia de direitos e à autonomia de homens e mulheres idosos: uma aproximação com os centros de idosos em Barcelona. 2011. 245 f. Tese (Doutorado em Serviço Social) - Faculdade de Serviço Social, Pontifícia Universidade Católica do Rio Grande do Sul, Porto Alegre, 2011.

LAKATOS, Eva Maria; MARCONI, Marina de Andrade. Metodologia científica: ciência e conhecimento científico, métodos científicos, teoria, hipóteses e variáveis. 5. ed. rev. e ampl. São Paulo: Atlas, 2007.

LOPES, Marize Amorim. Pessoas longevas e atividade física: fatores que influenciam a prática. 253 f. 2012. Tese (Doutorado em Educação Física) - Programa de PósGraduação em Educação Física, Universidade Federal de Santa Catarina, Florianópolis, 2012.

MARCELlinO, Nelson Carvalho. Estudos do lazer: uma introdução. Campinas: Autores Associados, 1996.

MARCELLINO, Nelson Carvalho. Lazer e cultura: algumas aproximações. In: Lazer e cultura. Campinas: Alínea, 2007. p. 9-30.

Lazer e humanização. Campinas: Papirus, 1983.

MARCONI, Marina de Andrade; LAKATOS, Eva Maria. Técnicas de pesquisa: planejamento e execução de pesquisas, amostragens e técnicas de pesquisa, elaboração, análise e interpretação dos dados. - 6. ed. São Paulo: Atlas, 2007.

MAZO, Giovana Zarpellon. Atividade física e qualidade de vida de mulheres idosas. 2003. 203 f. Dissertação de Doutoramento (Doutorado em Ciências do Desporto) Faculdade de Ciências do Desporto e de Educação Física, Universidade do Porto, Porto, 2003.

; LOPES, Marize Amorim; BENEDETTI, Tânia Bertoldo. Atividade física e o idoso: concepção gerontológica. 3. ed. rev. e ampl. Porto Alegre: Sulina, 2009.

MELLO, João Gabriel; VOTRE, Sebastião Josué. Fatores que interferem na participação de homens idosos em programas de esporte e lazer. Pensar a Prática, Goiânia, v. 16, n. 4, p. 956-1270, out./dez. 2013.

MELO, Victor Andrade; ALVES JÚNIOR, Edmundo Drummond. Introdução ao lazer. 2. ed. rev. e atual. Barueri: Manole, 2012.

Arte e lazer: desafios para romper o abismo. In: MARCELLINO, Nelson Carvalho (Org.). Lazer e cultura. Campinas: Alínea, 2007. p. 65-87.

Conteúdos culturais. In: GOMES, Christianne Luce (Org.). Dicionário crítico do lazer. Belo Horizonte: Autêntica, 2004. p. 51-54.

Educação estética e animação cultural: reflexões. Licere, Belo Horizonte, v. 5, n. 1, p. 101-113, 2002. 
MINAYO, Maria Cecília de Souza. O desafio da pesquisa social. In: social: teoria, método e criatividade. 31. ed. Petrópolis: Vozes, 2012. p. 9-30.

Pesquisa

. O desafio do conhecimento: pesquisa qualitativa em saúde. 13. ed. São Paulo:

Hucitec, 2013.

PMF - PREFEITURA MUNICIPAL DE FLORIANÓPOLIS. Critérios para o cadastramento na PMF/SEMAS/GCFV dos grupos de convivência de idosos, ano 2014. Florianópolis: Prefeitura Municipal de Florianópolis/Secretaria Municipal de Assistência Social/Gerência de Convivência e Fortalecimento de Vínculos, 2014. (impresso).

ROLLIN, Irma Silva. Grupos de convivência para terceira idade: uma busca do sentido de ser e de existir. 1998. 107 f. Trabalho de Conclusão de Curso (Graduação em Serviço Social) - Departamento de Serviço Social, Centro Socioeconômico, Universidade Federal de Santa Catarina, Florianópolis, 1998.

ROSA, Maria Cristina. As festas e o lazer. In: MARCELLINO, Nelson Carvalho (Org.). Lazer e cultura. Campinas: Alínea, 2007. p. 195-218.

SANTOS, Priscila Mari; MARINHO, Alcyane. Participação de homens e mulheres em grupos de convivência para idosos em Florianópolis (SC). In: ENCONTRO CATARINENSE DE GERONTOLOGIA, 6., 2014, Florianópolis. Anais... Florianópolis: Associação Nacional de Gerontologia de Santa Catarina - ANG/SC, 2014. p. 59-60.

SCOTT, Joan Wallach. Gênero: uma categoria útil de análise histórica. Educação e Realidade, Porto Alegre, v. 20, n. 2, p. 71-99, jul./dez. 1995.

O enigma da igualdade. Revista Estudos Feministas, Florianópolis, v. 13, n. 1, p. 11-30, jan./abr. 2005.

SIMMEL, Georg. Questões fundamentais da sociologia: indivíduo e sociedade. Rio de Janeiro: Jorge Zahar, 2006.

STUCCHI, Sérgio. Espaços e equipamentos de recreação e lazer. In: BRUHNS, Heloísa Turini (Org.). Introdução aos estudos do lazer. Campinas: Editora da Unicamp, 1997. p. $105-121$.

VARGAS, Alessandra Cardoso; PORTELLA, Marilene Rodrigues. O diferencial de um grupo de convivência: equilíbrio e proporcionalidade entre os gêneros. Revista Kairós Gerontologia, São Paulo, v. 16, n. 3, p. 227-238, jun. 2013.

\section{Endereço das Autoras:}

Priscila Mari dos Santos

Servidão Olindina Maria Lopes, 904, Campeche

Florianópolis - SC - 88066-028 
Endereço Eletrônico: priscilamarisantos@hotmail.com

Alcyane Marinho

Rua Vereador Ramon Filomeno, 357, ap. 1001 Torre 1. Parque São Jorge.

Florianópolis - SC - 88034-495

Endereço Eletrônico: alcyane.marinho@hotmail.com 